\section{Lift spending cap or lose Mars mission, ESA panel warns}

[MUNICH] Europe's space ministers have been told that a planned mission to Mars - known as Mars Express - will almost certainly have to be abandoned unless they lift a 'cap' placed two years ago on the science budget of the European Space Agency (ESA).

The warning came last week from members of ESA's Science Programme Committee (SPC). It forms part of a resolution outlining the consequences of the budget cap imposed at a ministerial meeting in 1995 . The cap has already led to a 9 per cent reduction in the budget of the science programme.

The resolution also warns of the threat to the concept of large 'cornerstone' missions, the backbone of ESA's long-term science plan, Horizons 2000. The agency could be left unable to plan its space science strategically, and hopes for a new cornerstone mission in fundamental physics would be dashed.

"Europe will have to restrict its space programme largely to niches left by other agencies," says the resolution. As a result, it would "lose the supranational leadership and visibility" which allowed it to emerge on the world scene.

The resolution endorses concern expressed earlier this month by ESA's Space Science Advisory Committee (see Nature 390, 8; 1997). As the SPC is made up of delegates from member states, it is closer to ministers than the advisory committee, whose 11 members are independent space scientists.

Nevertheless few feel that the programme committee is likely to influence the course of financial stringency on which Europe's space ministers seem set, particularly as any decision to restore full index-linking of the ESA budget would require unanimous support from member states. Several including Germany, Britain and Sweden remain opposed to lifting the funding limit.

But Johann Bleecker, director of the Dutch Space Research Organization, and one of his country's delegates to the SPC, hopes that an awareness that Europe's international status in space efforts could suffer if it abandons its independent mission to Mars will shake ministers out of their stubbornness.

One piece of good news was announced at the SPC meeting last week. After several years of negotiations, ESA has signed an agreement with the Russian Space Agency that Integral, the gamma-ray observatory, will be launched on a Russian Proton launcher on schedule in April 2001.

In exchange for the launch, Russian astronomers will have access to about a quarter of Integral's observing time. Integral was approved as the next ESA medium-sized mission in 1993.

Alison Abbott

\title{
NASA told to make greater use of 'cheaper' private data
}

[WASHINGTON] The US Congress last week gave the National Aeronautics and Space Administration (NASA) permission to build and launch a quick replacement for an ocean wind monitoring instrument lost when a Japanese satellite failed in orbit in June. But one member of Congress has accused NASA of not checking if the satellite data could be bought for less money.

NASA will spend $\$ 93$ million to fly its Quick Scatterometer (QuickSCAT) mission in November 1998. It will help to make up for the loss of a NASA-funded sensor on Japan's ADEOS Earth science satellite (see Nature, $\mathbf{3 8 8}, 105 ; 1997)$, which was to have provided data until the more capable SeaWinds is launched on ADEOS-II in 2000. Ocean wind data help predict the movement of tropical storms and are used in climate research.

QuickSCAT will be the latest experiment in cheap, fast space missions, with extremely short development and streamlined procurement of an 'off-the-shelf' satellite. The instrument itself will be built from SeaWinds spare parts to keep costs down.

Earlier this month, Dana Rohrabacher (Republican, California), chairman of the House of Representatives subcommittee for space, wrote to the NASA administrator, Daniel Goldin, praising him for picking a cheap, fast microsatellite for the job.

But he also claimed that "the commercial sector could provide this data immediately from existing satellite data streams". Buying a new satellite, he suggested, would therefore be a waste of money.

Rohrabacher declined to name companies that could provide the service. And last week Goldin told James Sensenbrenner (Republican, Wisconsin), chairman of the House Science Committee, that NASA knew of no commercial source of ADEOS-type sea surface wind data.

The compromise is for the agency to go ahead with QuickSCAT while issuing a formal request for data from commercial vendors. "If such data were available," Goldin wrote, "it could have the potential to achieve cost savings and/or the added benefit of a backup source of data if a problem were to arise with the QuickSCAT mission.”

Rohrabacher, Sensenbrenner and others in Congress accuse NASA of dragging its feet on buying science data, particularly Earth remote sensing data, from private companies. But NASA science managers say sometimes under their breath - that commercial data rarely meet their needs.

Congress, particularly the House Science Committee, has forced the issue by giving NASA \$50 million for commercial data pur-

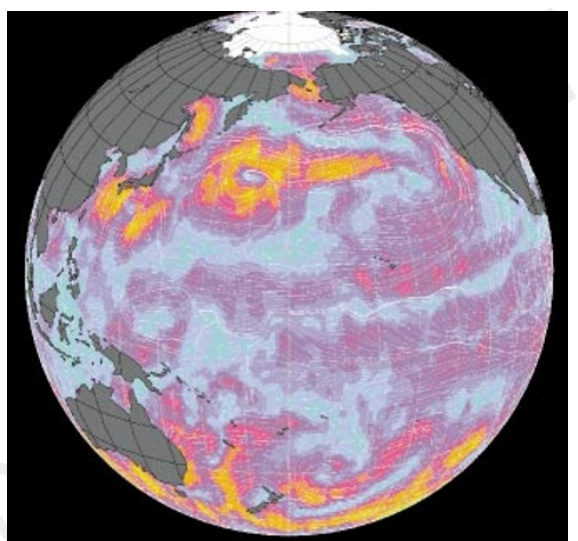

It's windy down there: ocean surface winds over the Pacific seen from a NASA Scatterometer.

chase in 1997, money that is so far unspent. NASA has also been ordered to report by next spring on "the extent to which the baseline scientific requirements of Mission to Planet Earth [the Earth science programme] can be met by commercial providers".

Last week, NASA showed some movement by announcing that 11 companies would receive up to six months funding to analyse and validate data products that might fit government scientific needs.

The agency also received encouraging news recently on another project to foster partnership in remote sensing between government and industry: the proposed LightSAR imaging radar satellite. Congress gave NASA \$12 million last year — money it had not requested - to begin planning for a satellite to take synthetic aperture radar (SAR) images of the Earth from orbit.

Such imagery can be used for studying crustal deformation, tracking the motion of ice sheets and examining ocean circulation patterns. At the same time, SAR is believed to have commercial applications from topographic mapping to crop monitoring.

The idea of LightSAR is that industry and government would share the estimated $\$ 150$ to $\$ 250$ million bill more or less equally. Last March, NASA asked four companies to study if such a partnership was commercially attractive. The preliminary answer, says LightSAR pre-project manager Steven Bard of the Jet Propulsion Laboratory, is yes.

"All the teams found that there is a very high market potential," he says, though he adds the market is also uncertain. Results will be presented to managers at NASA headquarters in January and mean there is a "good chance there will be a meaningful investment" by industry in LightSAR. If so, it would increase the chances of winning significant government funding in 1999, with a launch three years later.

TonyReichhardt 